\author{
EVS29 Symposium \\ Montréal, Québec, Canada, June 19-22, 2016
}

\title{
International Cooperation on Public Policies and Strategies for Hybrid \& Electric Vehicles under the International Energy Agency
}

\author{
James F. Miller ${ }^{1}$, Urs Muntwyler ${ }^{2}$ \\ ${ }^{1}$ IEA HEV-TCP Secretary-General (corresponding author) Argonne National Laboratory, \\ 9700 S Cass Ave, Argonne, IL, 60439 USA, james.miller@anl.gov \\ ${ }^{2}$ IEA HEV-TCP Chairman, Bern University of Applied Sciences, Jlcoweg 1, CH-3400, Burgdorf, Switzerland, \\ urs.muntwyler@bfh
}

\begin{abstract}
Summary
The International Energy Agency (IEA) established a Technology Collaboration Program (formerly called Implementing Agreement) on "Hybrid and Electric Vehicles" in 1994. Today there are 17 member countries that participate in 12 working groups related to electric vehicles, components, deployment, infrastructure, and environmental/economic issues. The current activities and recent key results from these working groups are described.
\end{abstract}

Keywords: HEV (hybrid electric vehicle), EV (electric vehicle), PHEV (plug in hybrid electric vehicle), federal government, deployment

\section{Introduction}

The International Energy Agency (IEA) is made up of 29 member countries and runs 39 collaborative research programs, designated as the Technology Collaboration Programs (formerly called Implementing Agreements). These programs foster the collaboration of researchers, organizations and companies. The aim is to speed up the technical and non-technical problem-solving in the field of technologies for energy efficiency, more efficient use of resources, and the use of renewable energies. The goal is a broader and more stable energy supply and a limitation of $\mathrm{CO}_{2}$ emissions. One of the key technologies is the motorized traffic. It is one of the major sources of $\mathrm{CO}_{2}$ emissions, it actually relies mainly on fossil energies and it is very energy-inefficient.

The "Hybrid and Electric Vehicles" (HEV-TCP) was founded in 1994. Today, the HEV-TCP has 17 participating member countries. The HEV-TCP member countries are Austria, Belgium, Canada, Denmark, Finland, France, Germany, Ireland, Italy, the Republic of Korea, the Netherlands, Spain, Sweden, Switzerland, Turkey, the United Kingdom, and the United States.

\section{Activities}

Every five years the Implementing Agreement prepares and delivers a new five-year work plan to the IEA headquarters. The work plan for 2015-2019 has been completed and approved. Under the new rules, participation of non-IEA countries is possible. This allows important countries in the production and the use of hybrid and electric cars to participate and to contribute to the international research activities.

The actual activities are carried out under working groups, or Tasks [1]. Countries join various Tasks depending upon their particular interests. An individual Task typically has about 3-8 participating countries. 
The twelve current working groups are:

- Task 1: "Information exchange” - Activities include country experts meetings, an annual report, a newsletter, and a web site (www.ieahev.org)

- Task 10: "Electrochemical systems" - Objective is to exchange information to advance battery and capacitor technology in focused working groups. Future workshop examples include response to battery fires, internal short circuits, and second use of vehicle batteries.

- Task 21: “Accelerated ageing testing for lithium-ion batteries" - Objectives are the development and application of accelerated testing procedures for analyzing the ageing of lithium-ion (Li-ion) batteries in various vehicle applications; and to share the data with the organizations responsible for the development of standard testing procedures that are harmonized between countries.

- Task 23: "Light electric vehicle parking and charging infrastructure" -- Objectives are to document existing solutions for best practice, create turnkey guidelines for local governments, and conduct workshops for interested communities.

- Task 24: "Economic impact assessment of e-mobility" - Objectives are to develop a methodology and collect data to monitor the economic perspective of e-mobility, get a better view on the value chain for e-mobility in general and more specific on the economic potential in the local e-mobility sector in each participating country or region, with a common value chain that has 4 main categories: electric vehicles, charging infrastructure, energy, and mobility services.

- Task 25: "Plug-in Electric Vehicles" -- Objectives are to compare full-function HEVs, PHEVs, and EREVs with advanced conventional powertrains (clean diesel, turbocharged direct injection petrol, CNG, other); to conduct a systematic cost methodology comparison (i.e. battery, multiple TCO models), and to conduct a systematic market penetration methodology comparison to evaluate policy alternatives to increase market size.

- Task 26: "Wireless power transfer for electric vehicles" - Objectives are to address interoperability and comparison of standards; discuss safety issues of misalignment, leakage fields, and debris tolerance; and begin cataloguing potential grid impacts.

- Task 27: "Electrification of transport logistic vehicles (eLogV)" - Objectives are to produce a summary of the status of technologies, implementations and hurdles; identify early niche markets and commercialization opportunities; and provide policy recommendations for further RD\&D activities.

- Task 28: "Home grids and V2X technologies" - Objectives are to analyze the technical and economic viability of vehicle to grid technology, produce a policy making toolbox, and define a technology roadmap.

- Task 29: "Electrified, connected, and automated vehicles" - Objectives are to analyze the potential technological synergies of electrification, connectivity and automation of road vehicles and derive research, development and standardization needs; study the business models combining electrification and connectivity /automation of road vehicles and identify the need for action by companies and/or governments; and to assess the impact of user/driver behavior on the combination of electrification, connectivity and automation and conclude on needs for measures in awareness and legislation.

- Task 30: “Assessment of the environmental effects of electric vehicles" - Objectives are to analyze the environmental effects of electric vehicles (EVs) on the basis of life cycle assessment (LCA), including the production, operation and the end of life treatment of the vehicles, and in comparison to conventional vehicles. Assessment will include effects of EVs on water, air, land use (resource consumption, waste management), and overall environmental effects and their assessment. 
- Task 31: "Fuels and energy carriers for transport" - Objectives are to provide policy makers with up-to-date insight in environmental and energy impacts of (PH)EVs compared to ICEVs (petrol and diesel); to assessing potential impacts of future developments in vehicle technology and energy systems (up to 2030); and to focus on life cycle GHG emissions and local pollutants, with noise and energy security.

\section{Key Results}

Some recent key results from the various working groups include, among others, the following:

- Electric Vehicle Business Models -- Global Perspectives. This volume collects insights from industry professionals, policy makers and researchers on new and profitable business models in the field of electric vehicles (EV) for the mass market. This book includes approaches that address the optimization of total cost of ownership. Moreover, it presents alternative models of ownership, financing and leasing. The editors present state-of-the-art insights from international experts, including real-world case studies. [2]

- Quick Charging Technology for Plug-in Electric Vehicles. A report on the current status of quick charging technology describes quick charging technology deployment developments and trends, discusses objectively how quick charging technology can contribute to the deployment of electric vehicles, and provides recommendations for setting up a roadmap for quick charging technology development and implementation.

- Life Cycle Assessment (LCA) of Electric Vehicles (EVs). The working group identified how electric drivetrain vehicles should be designed for optimal recyclability and minimal resource consumption. It also identified the best available technologies and practices for managing the materials in EVs at the end of their useful life, when the vehicle is dismantled.

- EV Ecosystems project. The HEV-TCP held workshops on creating EV cities of the future in Newcastle, London, Istanbul, Barcelona, and Los Angeles.[3]

- EV City Casebook. This report documents the results to share experiences on EV demonstration and deployment, identify challenges and opportunities, and highlight best practices for creating thriving EV ecosystems.[4]

\section{Conclusions}

The International Energy Agency's Hybrid and Electric Vehicle Technology Collaboration Program (HEVTCP) enables member parties to discuss their respective needs, share key information, and learn from an ever-growing pool of experience from the development and deployment of hybrid and electric vehicles.

\section{References}

[1] IA-HEV Annual Report over 2014, “Hybrid and Electric Vehicles: The Electric Drive Delivers”, April 2015, http://www.ieahev.org

[2] “Electric Vehicle Business Models: Global Perspectives”, David Beeton and Gereon Meyer, editors, Springer, ISSN 978-3-319-12243-4 (2015)

[3] “Success Factors for Hybrid and Electric Vehicle Deployment", http://www.ieahev.org/assets/1/7/iahev_outlook_2013.pdf

[4] EV CITY CASEBOOK - A Look at the Global Electric Vehicle Movement, https://www.iea.org/publications/freepublications/publication/EVCityCasebook.pdf 


\section{Authors}

James F. Miller

HEV-TCP Secretary-General

Argonne National Laboratory

9700 S Cass Ave, Bldg 362

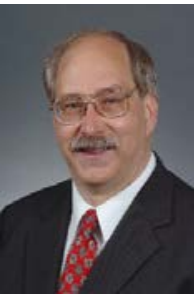

Argonne, IL 60439 (USA)

Tel: +1-630-252-3425

Email: james.miller@anl.gov

Dr. James Miller is Secretary-General of the International Energy Agency's Technology Collaboration Program on Hybrid and Electric Vehicles (HEV-TCP). He is also the Deputy Director of the Energy Systems Division at the US Department of Energy's Argonne National Laboratory. He received a Ph.D. in Physics from the University of Illinois, and MBA from the University of Chicago.

Urs Muntwyler

HEV-TCP Chairman

Bern University of Applied Sciences

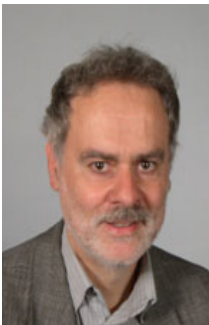

Jlcoweg 1

CH-3400 Burgdorf

Switzerland

Tel: (41) 798640084

Email: urs.muntwyler@bfh.ch

Urs Muntwyler is the Chairman of the International Energy Agency's Technology Collaboration Program on Hybrid and Electric Vehicles. He is also Professor for Photovoltaic at the Berne University of Applied Sciences in Burgdorf, Switzerland. 